\title{
Composição Química do Fruto de Imbuia (Ocotea porosa) Nativa do Município de Colombo, PR
}

\author{
Maria Lúcia Ferreira Simeone(1), Antonio Nascim Kalil Filho(2) \\ (1) Embrapa Milho e Sorgo, Rodovia MG 424, Km 45, Sete Lagoas,Caixa Postal 285, CEP 35701-970, Sete Lagoas-MG. E-mail: malu@cnpms.embrapa.br; ( \\ 2) Embrapa Florestas, Estrada da Ribeira, Km 111, CEP 83411-000, Colombo-PR. E-mail: kalil@cnpf.embrapa.br
}

\begin{abstract}
Resumo: O trabalho realizou a determinação da composição química do fruto (casca e semente) de Ocotea porosa (composição centesimal, macro e micronutrientes, teor de lipídios, ácidos graxos saturados e $\alpha$-tocoferol), procedentes de matrizes localizadas no Município de Colombo, PR. Os componentes para a casca e semente foram carboidratos $(54,4 \%)$, proteínas $(38,5 \%)$ e lipídios $(5,6 \%)$, e carboidratos $(33,4 \%)$, lipídios $(19,9 \%)$ e proteínas $(2,9 \%)$, respectivamente. A composição dos ácidos graxos do óleo da semente de Imbuia revelouse altamente saturada (89,9\% de ácidos graxos saturados), e como componentes principais, o ácido láurico (13,79\%), o ácido cáprico (2,46 \%) e o ácido mirístico (1,54\%). $\alpha$-tocoferol foi encontrado em ambas as partes na concentração igual a $180 \mathrm{mg} \cdot \mathrm{kg}^{-1}$ (sementes) e $120 \mathrm{mg} \cdot \mathrm{kg}^{-1}$ (casca). As sementes de Ocotea porosa constituem uma fonte significativa de proteínas e lipídios, sendo que o alto teor de ácido láurico demonstra potencial para o uso na indústria cosmética.
\end{abstract}

Termos para indexação: Óleo, ácido láurico, micro e macronutrientes, $\alpha$-tocoperol.

\section{Chemical Composition of the Fruit of Imbuia (Ocotea porosa) from Colombo, PR, Brazil}

\begin{abstract}
The aim of this work was to determine the chemical composition of Ocotea porosa fruit (rind and seed) (centesimal composition, macronutrients, micronutrients lipids, fatty acid distribution, and $\alpha$-tocopherol) from matrixes collected in Colombo, PR. The rind and seed components were carbohydrates (54.4\%), proteins (38.5\%) and lipids (5.6\%), and carbohydrates (33.4\%), lipids (19.9\%) and proteins (2.9\%), respectively. The fatty acid composition from Imbuia seed oil showed a percentual of $89.9 \%$ of saturated fatty acids, lauric $(11.49 \%)$, capric $(2.46 \%)$ and myristic $(1.54 \%)$ acids were the major components. $\alpha$-tocopherol was found in both compartment in concentration equal of $180.0 \mathrm{mg} \cdot \mathrm{kg}^{-1}$ (seeds) and $120 \mathrm{mg} \cdot \mathrm{kg}^{-1}$ (rind). Thus, the seeds of Ocotea porosa constitute a significant protein and lipids sources and the high concentration of lauric acid showed a potential use in cosmetic industry.
\end{abstract}

Index Terms:oil, lauric acid, micro and macronutrients, $\alpha$-tocopherol.

\section{Introdução}

O Brasil possui um grande número de espécies florestais nativas, sendo que as sementes de algumas delas revelaram-se boas fontes de nutrientes e óleos. Nos últimos anos, tem crescido a pesquisa nessa área para atender à demanda da indústria alimentícia, farmacêutica e cosmética, como por exemplo, a pesquisa com os óleos das sementes de andiroba, babaçú, bacuri, murumuru e cupuaçú (MORON-VILLARREYES, 1998).

A família Lauraceae é constituída por cerca de 30 gêneros, com distribuição marcadamente tropical e subtropical em todo o mundo, especialmente nas florestas centro e sul-americanas e, em sua maioria, por espécies lenhosas arbóreas. Possui considerável importância econômica, pois suas madeiras são usadas em construções leves e pesadas e em móveis de luxo; algumas são frutíferas, oleaginosas, usadas na medicina popular (RIZZINI; MORS, 1995).

A Ocotea porosa (Nees) L. Barroso pertence à família Lauraceae, sendo também conhecida como Imbuia. Sua ocorrência natural, segundo Carvalho (1994), vai da latitude $22^{\circ} 30^{\prime}$ a $29^{\circ} 50^{\prime} \mathrm{S}$, desde o Estado do Rio de Janeiro até o Rio Grande do Sul. Sua maior concentração ocorre em vastas áreas no norte do Estado de Santa Catarina, mas em manchas isoladas, cresce também na zona da Floresta Ombrófila Densa Atlântica (BALERONI et al., 2002). Conforme Lorenzi (1998), é uma planta semidecídua, que floresce durante os meses de outubro a novembro, com a maturação dos frutos entre janeiro a março. 
É utilizada como planta ornamental na arborização urbana, como planta apícola devido à atratividade de suas flores e no reflorestamento ambiental (CARVALHO, 1994). O fruto da Imbuia é uma baga globosa (esférica), de $13 \mathrm{~mm}$ a $17 \mathrm{~mm}$ de diâmetro, com superfície lisa, pesando 1,2 $\mathrm{g}$ a 2,3 g, o qual deve ser despolpado para a retirada da semente (KALIL FILHO et al., 2004; 2005). A semente é uma castanha, com superfície lisa, contendo numerosas estrias, com $12 \mathrm{~mm}$ a $15 \mathrm{~mm}$ de diâmetro. A semente divide-se em duas metades semi globulosas e deve ser coletada quando o fruto passa da coloração verde para violácea, podendo ser colhidos no chão, com coloração marrom.

A composição química das sementes é bastante variável, sendo que o ambiente onde crescem as plantas, a adubação e muitos outros fatores são capazes de alterar esta constituição, aumentando ou diminuindo a quantidade de certos componentes (LIBERAL; COELHO, 1980). Dentre os componentes químicos presentes em uma semente, destacam-se três grupos: proteínas, lipídios e carboidratos. Esta composição é definida geneticamente, podendo ocorrer influência de fatores ambientais (McDONALD, 1999; SATTLER et. al, 2004; CARVALHO; NAKAGAWA, 2000).

O conhecimento do teor e perfil de ácidos graxos e quantidade de tocoferóis são importantes, pois as reações peroxidativas em lipídios são as maiores causas de deteriorações das sementes durante o processo de armazenamento (FERGUSON et. al, 1990; McDONALD, 1999). Por isso, o estudo dos teores de tocoferóis (Vitamina E) é essencial para compreender os mecanismos de oxidação de substratos nas diferentes etapas de utilização das sementes (SATTLER, et. al, 2004).

Para subsidiar futuros estudos sobre o aproveitamento de Ocotea porosa, torna-se prioritário realizar a análise da composição centesimal de seus frutos.

Portanto, o objetivo desse trabalho foi realizar a determinação da composição química, de micro e macronutrientes, teor de tocoferóis e perfil de ácidos graxos do fruto de Ocotea porosa procedente de matrizes localizadas do Município de Colombo, PR.

\section{Material e Métodos}

Os frutos de Imbuia foram colhidos, em fevereiro de 2004, no Imbuial da Roseira, localidade do Município de Colombo, PR. As análises da composição química do fruto foram realizadas no laboratório de Nutrição de Plantas da Embrapa Florestas. As análises do perfil de ácidos graxos e teor de $\alpha$-tocoferol foram realizadas pelo laboratório Laboran.

Os frutos foram despolpados manualmente e separados em casca e semente e, em seguida, secos em estufa ventilada a $60{ }^{\circ} \mathrm{C}$, triturados em moinho tipo Willey, homegeneizados e analisados.

A composição centesimal aproximada da casca e semente quanto à umidade, cinzas, lipídios e proteínas, foi determinada pelos métodos descritos nas Normas Analíticas do Instituto Adolfo Lutz (ZENEBON; PASCUET, 2005). Para a determinação do teor da matéria seca, foi utilizado o método gravimétrico, no qual as amostras foram secas em estufa a $105^{\circ} \mathrm{C}$ até a obtenção de peso constante. $\mathrm{O}$ teor de nitrogênio total foi determinado pelo método microkjeldahl, sendo o teor protéico determinado multiplicando-se o conteúdo de nitrogênio total pelo fator 6,25 . Os lipídios foram determinados por extração contínua com éter etílico em aparelho de Sohxlet, à temperatura de $45-50{ }^{\circ} \mathrm{C}$ por aproximadamente 8 horas, após as quais o solvente foi recuperado e os recipientes contendo o extrato etéreo foram resfriados em dessecador e pesados, obtendose o valor de lipídios por diferença gravimétrica. $\mathrm{O}$ percentual de cinzas foi determinado por carbonização e incineração das amostras em mufla à temperatura de $550{ }^{\circ} \mathrm{C}$ por aproximadamente 4 horas. Os carboidratos totais foram calculados por diferença.

Osácidos graxos foram determinados por cromatografia gasosa, a partir da obtenção de ésteres metílicos de ácidos graxos. Para tanto, uma alíquota contendo 150 mg de lipídios obtidos do extrato etéreo, tanto da casca quanto da semente, foi submetida à saponificação com $\mathrm{NaOH} 0,5 \mathrm{~N}$ em metanol e esterificada com $\mathrm{BF}_{3}$ em metanol por meio de aquecimento, conforme descrito por Christie (1987). Os ésteres metílicos obtidos foram extraídos em funil de decantação com hexano grau Cromatografia Líquida de Alta Eficiência (CLAE) (MORRISON; SMITH, 1964). A identificação dos ésteres metílicos foi realizada em equipamento marca Shimadzu, modelo GC-17A, com detector de ionização de chama. Os ésteres metílicos foram separados em coluna capilar de sílica fundida $50 \mathrm{~m}$, com diâmetro interno $0,25 \mathrm{~cm}$ e espessura do filme $0,20 \mu \mathrm{m}$. Foram obedecidas as seguintes condições de operação do cromatógrafo gasoso: temperatura programada da coluna: $80^{\circ} \mathrm{C}$ a $220^{\circ} \mathrm{C}\left(5^{\circ} \mathrm{C} / \mathrm{min}\right)$; temperatura do injetor: 
$230{ }^{\circ} \mathrm{C}$; temperatura do detector: $240{ }^{\circ} \mathrm{C}$; gás de arraste, nitrogênio, velocidade linear: $40 \mathrm{~mL} / \mathrm{min}$. Os ácidos graxos foram identificados através da comparação dos tempos de retenção de padrões puros dos ésteres metílicos de ácidos graxos com os componentes separados das amostras (Lipid Standard SIGMA - Fatty acid methyl ester mixtures 47885). A quantificação foi feita com padrão interno, tricosanato de metila (23:0) conforme Zenebon e Pascuet (2005).

$\mathrm{O} \alpha$-tocoferol foi quantificado por cromatografia líquida de alta eficiência (CLAE), de acordo com o método da American Oil Chemists Society (1996). O óleo extraído das amostras a partir do extrato etéreo foi dissolvido em n-hexano, filtrado em membrana de $0,45 \mu \mathrm{m}$ e submetido diretamente à análise por CLAE. Empregou-se um sistema de cromatografia líquida de alta eficiência marca Shimadzu, com detecção por fluorescência (RF-10AXL) nos comprimentos de onda de excitação $290 \mathrm{~nm}$ e emissão $330 \mathrm{~nm}$. Condições extras: coluna de sílica com partículas de $5 \mu \mathrm{m}, 250$ $\mathrm{mm}$ de comprimento e 4,6 mm de diâmetro interno. A fase móvel utilizada foi n- hexano/isopropanol (99,5:0,5 $\mathrm{v} / \mathrm{v}$ ) com fluxo de $1,2 \mathrm{~mL} / \mathrm{min}$. Os solventes empregados foram de grau CLAE. Todas as soluções foram preparadas utilizando-se água ultrapura, obtida através do sistema Milli-Q (Millipore). $\mathrm{O} \alpha$ - tocoferol foi identificado por comparação com o tempo de retenção do padrão puro de $\alpha$-tocoferol (Sigma) analisado nas mesmas condições. A quantificação foi realizada por padronização externa e os valores foram calculados a partir de uma curva de calibração e expressos em mg.kg-1.

Para a determinação dos minerais (macro e micronutrientes), pesaram-se amostras de um grama, que foram homogeneizadas com $20 \mathrm{~mL}$ de solução contendo ácido nítrico e ácido perclórico $(5: 1 \mathrm{v} / \mathrm{v})$ e deixada em repouso por 12 horas. A mistura foi aquecida gradativamente até $120^{\circ} \mathrm{C}$ por 2 horas. Aumentou-se a temperatura lentamente para $210^{\circ} \mathrm{C}$ e manteve-se constante até que o extrato se tornasse incolor. Os tubos foram resfriados e tiveram o volume completado para $50 \mathrm{~mL}$ com água deionizada. Os minerais $(\mathrm{Ca}, \mathrm{Cu}$, $\mathrm{Fe}, \mathrm{Mg}, \mathrm{Mn}, \mathrm{Zn}$ ) foram quantificados nas amostras solubilizadas pela técnica da Espectrometria de Absorção Atômica de chama, em aparelho Perkin Elmer, modelo 3300 (ASSOCIATION OF OFFICIAL ANALYTICAL CHEMISTS, 1990). O fósforo foi determinado pelo método de Chen et. al (1956), em colorímetro Micronal, e os minerais potássio e sódio pelo método de fotometria de chama, em aparelho Micronal, de acordo com os procedimentos da Association of Official Analytical Chemists (1990).

Todas as determinações foram realizadas com cinco repetições.

\section{Resultados e Discussão}

A composição centesimal dos frutos (casca e semente) de Imbuia está apresentada na Tabela 1.

Os componentes majoritários para a casca foram carboidratos $(54,4 \%)$, proteínas $(38,5 \%)$ e lipídios (5,6\%), e, carboidratos (33,4\%), lipídios (19,9\%) e proteínas $(2,9 \%)$, para a semente.

Baleroni et al. (2002) relataram valores de lipídios 11,0 g. $100 \mathrm{~g} \mathrm{~g}^{-1}$, carboidratos $20,2 \mathrm{~g} .100 \mathrm{~g}^{-1}$ e proteínas 83,4 g. $100 \mathrm{~g}^{-1}$ para sementes de Imbuia provenientes de Rolândia, PR, diferentes dos valores encontrados para os parâmetros analisados de composição centesimal para a região de Colombo, PR (Tabela 1). A análise química realizada por Tonin et al. (2006), sobre a qualidade fisiológica das sementes de Imbuia, apresenta quantidades de carboidratos $\left(21,20 \mathrm{~g} .100 \mathrm{~g}^{-1}\right)$ maiores que lipídios $(17,66$ g.100 g-1) e proteínas $(3,38$ g.100 $\left.\mathrm{g}^{-1}\right)$, e próximas aos valores encontrados na população estudada neste trabalho. Em relação ao resíduo mineral fixo (cinzas), constatou-se baixo teor. A fração na semente mostrou-se superior à da casca $(1,7$ e 0,3 g. $100 \mathrm{~g}^{-1}$, respectivamente). Ainda assim, esses teores são considerados baixos, levando-se em consideração que sementes de outras espécies podem atingir teores superiores a $5 \%$ (NOLLET, 1996).

Esses resultados são de fundamental importância para o melhor entendimento de estudos relacionados às estratégias de germinação e dispersão das sementes desta espécie em condições de cerrado e mata Atlântica. 
Tabela 1. Composição centesimal aproximada $\left(\mathrm{g} \cdot 100 \mathrm{~g}^{-1}\right)$ dos frutos de Imbuia (Ocotea porosa)*.

\begin{tabular}{lcc}
\hline \multicolumn{1}{c}{ Componentes } & Valores (média \pm DP) Casca & Valores (média \pm DP) Semente \\
\hline Substâncias voláteis a $105{ }^{\circ} \mathrm{C}$ (umidade) & $1,2 \pm 0,1$ & $42,1 \pm 0,3$ \\
Resíduo mineral fixo (cinzas) & $0,3 \pm 0,1$ & $1,7 \pm 0,2$ \\
Lipídios & $5,6 \pm 0,3$ & $19,9 \pm 0,2$ \\
Proteínas (N x 6,25) & $38,5 \pm 0,1$ & $2,9 \pm 0,1$ \\
Carboidratos totais** & $54,4 \pm 0,2$ & $33,4 \pm 0,3$ \\
* média de cinco repetições; ** calculado por diferença; DP: desvio padrão.
\end{tabular}

No que se refere à composição dos ácidos graxos (Tabela 2), o óleo da semente de Imbuia revelou-se altamente saturado $(89,9 \%$ de ácidos graxos saturados do total de lipídios), apresentando como componente principal o ácido láurico (13,79\%). Por diferença, os ácidos graxos insaturados representam $10,1 \%$ do teor de lipídios na semente de Imbuia.

O ácido láurico (ácido dodecanóico) ocorre extensivamente em outras sementes da família das Lauraceae. É o ácido graxo dominante no óleo de cinamono (80-90 \%) e óleo de côco (41-56 \%), conforme citado por Walters et al. (2003).

O grande interesse do setor industrial nos óleos vegetais com alto teor de ácido láurico ocorre em função desse ácido ser utilizado principalmente como flavorizante no setor alimentício e surfactante na indústria cosmética, sabões e detergentes, pelo seu alto poder espumante e por ser biodegradável (CREWS et al., 2006).Outro aspecto importante do ácido láurico é sua atividade antifúngica, exibida contra fungos fitopatogênicos (WALTERS et. al., 2003).

O resultado obtido para a análise de $\alpha$-tocoferol (vitamina E) no óleo da casca (120 mg.kg-1) e semente (180 mg.kg ${ }^{-1}$ ) do fruto de Imbuia enquadra-se nos limites referenciados na literatura para os óleos de soja (9 - 352 mg. $\mathrm{kg}^{-1}$ ) e de milho (23-573 mg.kg ${ }^{-1}$ ) (FERRARI, 2001).

A alta saturação do óleo, tanto da casca, como da semente do fruto de Imbuia, conferem maior estabilidade oxidativa em condições normais de temperatura, umidade e luminosidade. Já a presença de $\alpha$-tocoferol (vitamina E), antioxidante natural, pode contribuir também para a sua estabilidade química (WANG et. al, 1998).

Os teores dos macros e micronutrientes da semente de Imbuia estão apresentados na Tabela 3.

Tabela 2. Composição em ácido graxo (gordura saturada g.100 $\mathrm{g}^{-1}$ ) e tocoferóis totais ( $\left.\mathrm{mg} \mathrm{kg}^{-1}\right)$ do óleo dos frutos de Imbuia (Ocotea porosa)*.

\begin{tabular}{lcc}
\hline Ácidos graxos & Valores obtidos (média \pm DP) Casca & Valores obtidos (média \pm DP) Semente \\
\hline 6:0 ac. capróico & $<\mathbf{0 , 0 5} \pm \mathbf{0 , 0 1}$ & $<\mathbf{0 , 0 5} \pm \mathbf{0 , 0 1}$ \\
8:0 ac. caprílico & $<\mathbf{0 , 0 5} \pm \mathbf{0 , 0 1}$ & $<\mathbf{0 , 0 5} \pm \mathbf{0 , 0 1}$ \\
10:0 ac. cáprico & $\mathbf{0 , 9 0} \pm \mathbf{0 , 0 3}$ & $\mathbf{1 , 5 6} \pm \mathbf{0 , 0 3}$ \\
12:0 ac. láurico & $\mathbf{2 , 3 0} \pm \mathbf{0 , 0 4}$ & $\mathbf{1 1 , 4 9} \pm \mathbf{0 , 0 4}$ \\
14:0 ac. mirístico & $\mathbf{1 , 4 5} \pm \mathbf{0 , 0 3}$ & $\mathbf{0 , 0 9} \pm \mathbf{0 , 0 1}$ \\
$16: 0$ ac. palmítico & $<\mathbf{0 , 0 5} \pm \mathbf{0 , 0 1}$ & $\mathbf{0 , 0 9} \pm \mathbf{0 , 0 1}$ \\
$18: 0$ ac. esteárico & $<\mathbf{0 , 0 5} \pm \mathbf{0 , 0 1}$ & $<\mathbf{0 , 0 5} \pm \mathbf{0 , 0 1}$ \\
$\alpha$-Tocoferol & $\mathbf{1 2 0} \pm \mathbf{2 , 3 0}$ & $\mathbf{1 8 0} \pm \mathbf{3 , 6 0}$
\end{tabular}

* média de cinco repetições; DP: desvio padrão. 
Tabela 3. Teores de minerais $\left(\mathrm{g} \mathrm{kg}^{-1}\right)$ dos frutos de Imbuia (Ocotea porosa)*.

\begin{tabular}{ccc}
\hline Elementos & Valores $(\mathbf{m e ́ d i a} \pm \mathbf{D P})$ Casca & Valores (média \pm DP) Semente \\
\hline Cálcio & $1,49 \pm 0,03$ & $0,20 \pm 0,01$ \\
Cobre & $0,06 \pm 0,01$ & $0,08 \pm 0,01$ \\
Ferro & $0,17 \pm 0,02$ & $0,16 \pm 0,02$ \\
Fósforo & $1,27 \pm 0,04$ & $1,80 \pm 0,03$ \\
Magnésio & $1,08 \pm 0,03$ & $0,60 \pm 0,04$ \\
Manganês & $0,19 \pm 0,02$ & $0,06 \pm 0,01$ \\
Potássio & $13,53 \pm 0,05$ & $9,13 \pm 0,04$ \\
Zinco & $0,15 \pm 0,01$ & $0,02 \pm 0,01$ \\
\hline
\end{tabular}

Tanto para a semente quanto para a casca, o macronutriente potássio exibiu a maior concentração $\left(9,13\right.$ e $\left.13,53 \mathrm{~g} \mathrm{~kg}^{-1}\right)$, seguido do fósforo $(1,80 \mathrm{e}$ $\left.1,27 \mathrm{~g} \cdot \mathrm{kg}^{-1}\right)$ e magnésio $\left(0,60\right.$ e $\left.1,08 \mathrm{~g} \cdot \mathrm{kg}^{-1}\right)$. O teor de cálcio foi maior na casca $\left(1,49 \mathrm{~g} \cdot \mathrm{kg}^{-1}\right)$ do que na semente $\left(0,20 \mathrm{~g} \cdot \mathrm{kg}^{-1}\right)$, sendo que o fósforo desempenha, também, um importante papel no processo germinativo da semente (POPINIGIS,1985). Embora a participação dos micronutrientes (cobre, ferro, manganês e zinco) tenha sido pequena, tanto para a casca quanto para a semente, a falta de qualquer um deles pode resultar em modificações significativas no teor de proteínas, lipídios e carboidratos (BARBOSA FILHO et al., 2001).

É importante ressaltar que as diferenças na composição química dos frutos de O. porosa das diferentes regiões podem ser explicadas pela diferença na fase de desenvolvimento e maturação que elas se encontram, bem como, pela influência dos fatores bióticos e abióticos.

\section{Conclusão}

Os frutos de Imbuia (Ocotea porosa) constituem uma fonte significativa de proteínas e lipídios, sendo que o alto teor de ácido láurico e a presença de $\alpha$-tocoferol (vitamina E) sugerem a aplicação desse substrato no desenvolvimento de produtos para a indústria de cosméticos e fitoterápicos.

\section{Referências}

AMERICAN OIL CHEMISTS SOCIETY. Official methods and recommended practices of the American oil chemists society. 4. ed. Champaign: 1996.

ASSOCIATION OF OFFICIAL ANALYTICAL CHEMISTS. Official methods of analysis of the association of official analytical chemists. 15 ed., Washington, 1990.

BALERONI, C. R. S.; MORAES, M. L. T.; MORAES, S. M. B.; SOUZA, C. S.; SÁ, M. E. Composição química de sementes das espécies florestais mamica-de-cadela (Brosimum gaudichaudii Trec), marolo arbóreo (Annona crassiflora Mart.), marolo rasteiro (Annona dióica St. Hil.), chichá-do-cerrado (Ssterculia a St. Hil.

Ex Turpin) e Imbuia (Ocotea porosa (Nees) L. Barroso). Ciências Agrárias e da Saúde. FEA, Andradina, v. 2, n. 1, p. 28 - 32, 2002.

BARBOSA FILHO, M. P.; CANTARELLA, H.; WIETHOLTER, S. Micronutrientes para culturas anuais: Arroz, milho e trigo. In: Manuel Evaristo Ferreira; Mara Cristina Pessôa da Cruz. (Org.). Micronutrientes na Agricultura. Jaboticabal, SP: Editora Legis Summa Ltda, 2001, v. 1, p. 285-318.

CARVALHO, N. M.; NAKAGAWA, J. Sementes: ciência, tecnologia e produção. 4 ed. Jaboticabal: FUNEP, 2000, 588 p.

CARVALHO, P. E. R. Espécies brasileiras: recomendações silviculturais, potencialidades e uso da madeira. Colombo: EMBRAPA -CNPF; Brasília, DF: EMBRAPA-SPI, 1994. 639 p.

CHEN, O. S.; TORIBARA, T. Y.; WARMER, H.

Microdetermination of phosphorus. Analytical Chemistry, Washington, v. 28, n. 11, p. 1756-1759, 1956. 
CREWS, C.; HOUGH, P.; GODWARD, J.; BRERETON, P.; LEES, M.; GUIET, S.; WINKELMANN, W. Quantification of the main constituints of some authentic grape-seed oil of different origin. Journal of Agriculcultural and Food Chemistry, Washington, v. 54, n. 17, p. 6261-6265, 2006.

CHRISTIE, W. W.; Lipid Analysis, $2^{\text {nd }}$ ed., Pergamon Press: Oxford, 1987.

FERRARI, R. A. Componentes minoritários de óleos vegetais. Óleos e Grãos, v. 58, p. 20-28, 2001.

FERGUSON, J. M.; TEKRONY, D. M.; EGLI, D. M. Changes during early soybeans seed and axes deterioration: II Lipids. Crop Science, Madison, v. 30, p. 179-182, 1990.

KALIL FILHO, A. N. ; MARZOLLO, L. G.; REGO, G. M. ; HIRANO, E.; STURION, J. A.; LOPES, A. J. Associação entre diâmetro e peso com emergência de sementes de imbuia (Ocotea porosa) em viveiro 2005. Colombo: Embrapa Florestas, 2005. (Embrapa Florestas. Comunicado técnico, 138).

KALIL FILHO, A. N.; HIRANO, E.; NICOLOTTI, F.; RESENDE, M. D. V. Componentes de variância de características de sementes de duas populações de imbuia (Ocotea porosa Nees et Martius ex. Nees, Lauraceae de Santa Catarina. Boletim de Pesquisa Florestal, Colombo, PR, v. 48, p. 111-115, 2004.

LIBERAL, O. H. T.; COELHO, R. C. Manual do laboratório de análise de sementes. Niteroi: PESAGRO-Rio, 1980. v. 1, 95 p.

LORENZI, H. Árvores brasileiras: manual de identificação e cultivo de plantas arbóreas nativas do Brasil. Nova Odessa: Instituto Plantarum de Estudos da Flora, 1998. v. 2 , 352 p.

McDONALD, M. B.; Seed deterioration. Physiology, repair and assessment. Seed Science Technology, v. 27, p. 177-237, 1999.

MORRISON, W. R.; SMITH, L. M. Preparation of fatty acid methyl esters and dimethyl acetals from lipids with boron fluoride methanol. Journal of Lipid Research, v. 5, n. 4, p. 600-608, 1964.
MORON-VILLARREYES, J. A. Óleos vegetais. In: Tópicos especiais em tecnololgia de produtos naturais. 1. Ed. Belém, PA: Editora da UFPA - NUMS/POEMA, 1998.

NOLLET, L. M. L. (Ed.) Handbook of food analysis: physical characterization and nutrient analysis. New York: Marcel Dekker, 1996.

ZENEBON, O.; PASCUET, N. S. (Coord.). Normas analíticas do Instituto Adolfo Lutz. 4. ed. São Paulo: Instituto Adolpho Lutz, 2005. 1020 p.

POPINIGIS, F. Fisiologia da Semente. 2.ed. Brasília: [s.n.], 1985. 289 p.

RIZZINI, C. T.; MORS, W. B. Botânica Econômica Brasileira. 2 ed., Rio de Janeiro: Âmbito Cultural Edições Ltda., 1995, 248p.

SATTLER, S. E.; GILLILAND, L. U.; LUNDBACK, M. M.; POLLARD, M.; DELLAPENNA, D. Vitamin E is essential for seed longevity and for preventing lipid peroxidation during germination. The Plant Cell, v. 16, p. 1419-1432, 2004.

TONIN, G. A.; PEREZ, S. C. J. G. A. Qualidade fisiológica de sementes de Ocotea porosa (Nees et Martius ex. Nees) após diferentes condições de armazenamento e semeadura. Revista Brasileira de Sementes, v. 28, p. 26-33, 2006.

WALTERS, D. R.; WALKER, R. L.; WALKER, K. C. Lauric acid exhibits antifungal activity against plant pathogenic fungi. Journal of Phytopathology, v. 151, p. 228-230, 2003.

WANG, C.; NING, J.; KRISHNAN, P.G.; MATTHEES D. P. Effects of steeping conditions during wet-milling on retention of tocopherols and tocotrienols in corn. Journal of American Chemistry Society, v. 75, p. 609-613, 1998.

Recebido em 11 de junho de 2008 e aprovado em 04 de setembro de 2009 